\title{
The Present State of Surgical Rehabilitation of the Upper Limb in Tetraplegia
}

\author{
Erik Moberg, M.D. \\ Göteborgs Universitet Medicinska Fakulteten, Ortopedisk-kirurgiska Institutionen \\ 1, Sahlgrenska Sjukhuset, S-413 45, Göteborg, Sweden
}

New developments in hand surgery, expanding rapidly after the Second World War, did not find acceptance for surgery in this field. A totally new way of thinking was needed to overcome strong resistance against surgery.

There can be problems with this new and very useful surgery in tetraplegia but they can be overcome. It is necessary to find a surgeon willing to build up over several years the necessary personal experience to provide a lead and build up the necessary team around him. Routine physiotherapy after surgery will easily lead to disaster and nothing of value can be achieved through a consultant surgeon visiting the Spinal Unit infrequently.

The new concepts of management of the upper limbs in tetraplegia can be obtained by reading recent publications, but this application in the individual case can be achieved only by experience, by starting with simple cases and by slow advancement to the more complex.

Two errors in early cases led to disappointment: (1) the belief that it was a pure motor problem to be solved in the same way as in poliomyelitis. And so the loss was seriously underestimated (Table I). Sensation and proprioception tended to be underestimated. (2) Too much concentration was made on providing gripping functions, especially opposition and so surgery which was too complex was used. Other functions of the hand, especially those for human contact, and the aesthetic aspects were underestimated.

Also statistics show that in the U.S.A. and Scandinavia some 80 per cent of all tetraplegia cases will have very limited muscle function and sensory appreciation. Therefore, the key to providing useful improvement in function

Table I The loss. A comparison

\begin{tabular}{lccc}
\hline & Normal hand & Polio hand & Tetraplegic hand \\
\hline $\begin{array}{l}\text { Ligaments reliable for } \\
\text { stability }\end{array}$ & 45 & 45 & $3-4$ \\
$\begin{array}{l}\text { Muscles below elbow } \\
\text { which are functional (gr. 4) } \\
\text { or suitable for transfer }\end{array}$ & 37 & $\begin{array}{l}\text { Variable but } \\
\text { usually } 4-8\end{array}$ & In $85^{\circ} \%$ of cases $0-2$ \\
$\begin{array}{l}\text { Tactile gnosis } \\
\text { Proprioception }\end{array}$ & $\begin{array}{l}\text { Normal } \\
\text { Normal }\end{array}$ & $\begin{array}{l}\text { Normal } \\
\text { Normal }\end{array}$ & $\begin{array}{l}\text { Usually greatly reduced or absent } \\
\text { Usually greatly reduced or absent }\end{array}$ \\
\hline
\end{tabular}



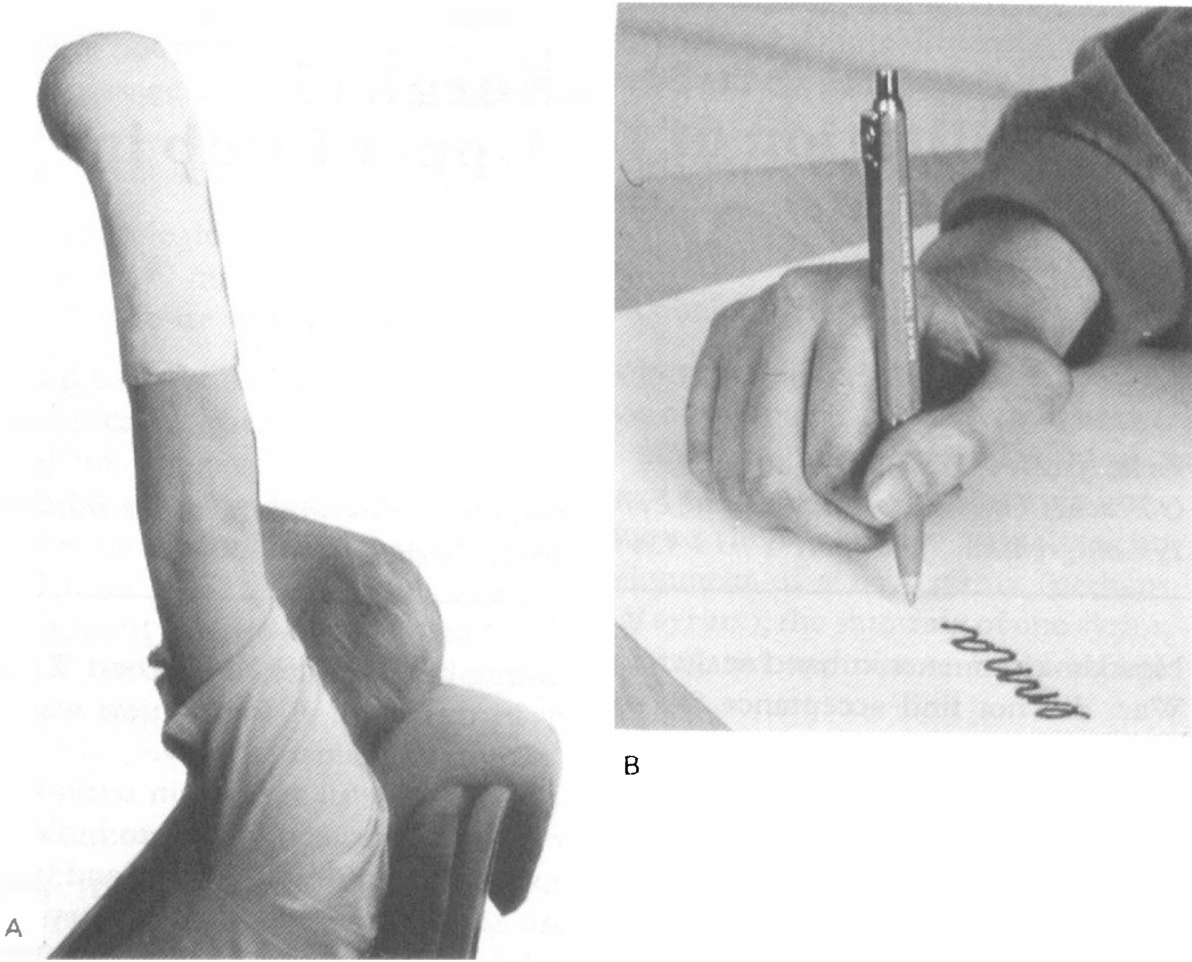

B

Figure 1 This arm had no triceps function and no useful sensory function in the hand. Therefore position and motion of the digits had to be controlled by vision alone. The only functional muscles below elbow (force $4(\mathrm{MRC})$ ) were brachioradialis and wrist extensors. (A) elbow extension has been restored by transfer of the biceps muscle. (Note the plaster on the hand following flexor pollicis longus tenodesis to radius recently performed.) (B) shows how in this way a strong key grip can be obtained.

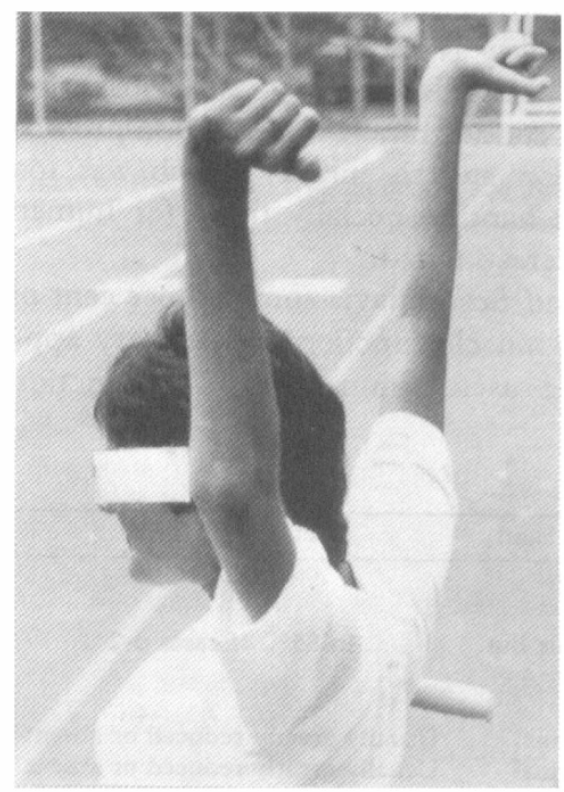

Figure 2 Another way to obtain elbow extension. The patient wanted especially to swim, almost impossible without elbow extensors. In both arms the posterior part of the deltoid was used to give such extension. Now she enjoys swimming, but of course other activities are improved also. No functional loss. 


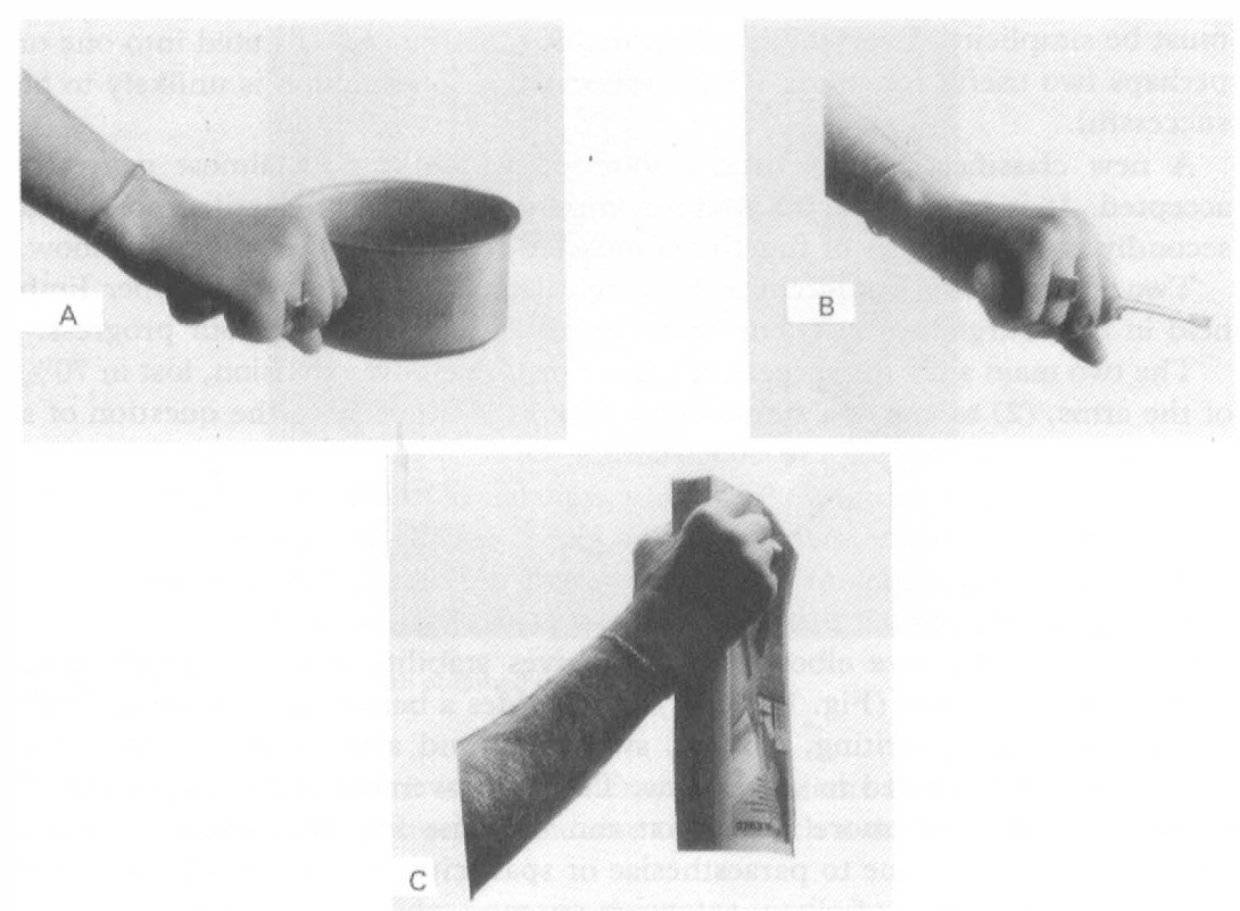

Figure 3 This young man had in the right arm triceps force 3 (weak, but useful extension against gravity), a two point discrimination of $5 \mathrm{~mm}$ at all digital pulps and below elbow brachioradialis, pronator and wrist extensors all of force 4 (MRC). No active mobility at all in finger flexors and extensors. He wanted especially three functions: to be able to handle a pan, to use a screwdriver for repairing cassette recorders, and to lift in the thumb grip heavier objects. By open exploration and testing it was found that the extensor carpi radialis brevis alone could lift 5 $\mathrm{kg}$ and was strong enough to handle wrist extension alone. Extensor carpi radialis longus could be used for finger flexion and was transferred to the profundi flexors. At the same time the flexor pollicis longus tendon was used as a transpalmar tenodesis into lower radius for a key thumb grip. The distal thumb joint was stabilised by a $2 \mathrm{~mm} \mathrm{~K}$-wire. (A) now he can easily handle the stewpan (B) admittedly still a bit clumsy using the screwdriver and (C) lifting a telephone book.

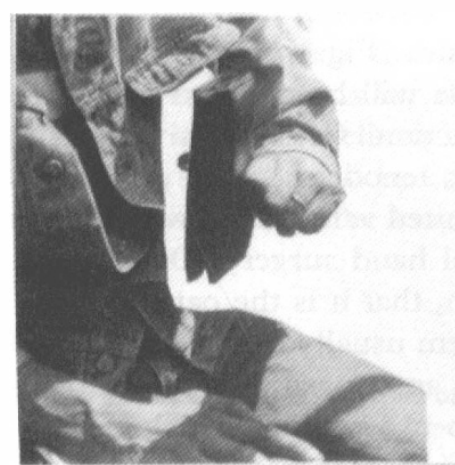

A

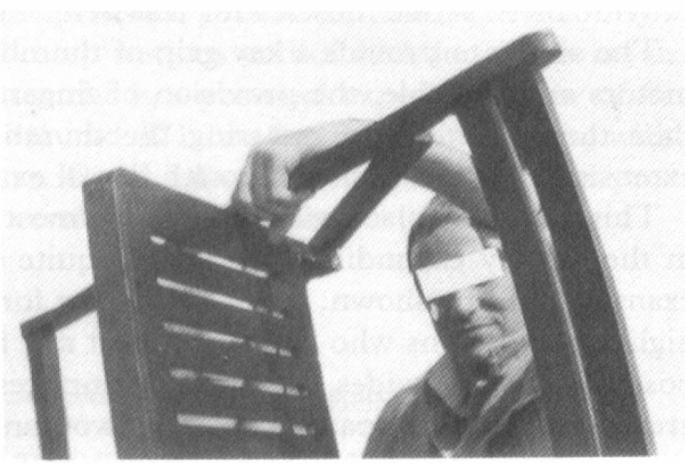

B

Figure 4 Young man without activity in flexor and extensor muscles to the left hand, but $5 \mathrm{~mm}$ two point discrimination at finger pulps to the thumb and the index. The same surgery was performed as in the case in Figure 3. With his new function (A) he is holding a pocketbook in the key grip and $(\mathbf{B})$ is lifting a wooden chair with his strong finger flexors, directly moved by the extensor carpi radialis longus. Obs: The flexion is strong even with the wrist flexed. 
must be simplicity. Everything still available must be concentrated into one or perhaps two useful functions. More elaborated reconstruction is unlikely to be successful.

A new classification has been elaborated which is now almost generally accepted. It is based first on afferent impulses, vision and tactile gnosis and secondly on the number of functional muscles of grade 4 or more below elbow.

Two international conferences on surgical rehabilitation of the upper limb held in Edinburgh and in Giens (France) have greatly added to our progress.

The two main aims for surgery are (1) to restore elbow extension, lost in $70 \%$ of the arms, (2) to create a single hand grip. It is often more the question of a new construction than of a re-construction.

The first aim is achieved through a transfer of the deltoid muscle to the triceps tendon or to the olecranon. The gap is usually bridged by free tendon grafts. If a strong supinator muscle is present the biceps can be transferred to the triceps tendon to get the desired elbow control.

Restoration of active elbow extension gives stability which is much more important than power (Fig. 1, Fig. 2). It provides a better range of upper limb activity for eating, writing, driving, swimming and also, in a few cases, for better transfer from bed to wheelchair. This improvement is often appreciated by the patients even more than what can be done for hand function. Even where, for example, due to paraesthesiae or spasticity, nothing can be done for the hands, restoration of elbow extension surgery can be worthwhile.

To improve hand function is an individual problem and can only be learned through experience and with the closest collaboration of the patients. Usually, if both hands can be improved it is wise to provide them with differing functional abilities (Fig. 3). For example, one hand can be given a narrower but stronger thumb grip, the other a weaker grip, but which can be opened for handling a glass of water or a beer can. The principle is almost always to lead a more proximal function such as wrist extension to provide a more distal function such as a strong thumb grip. Tenodeses and tendon transfers are the usual methods used. Active wrist extension should never be given up by arthrodesis in order to provide more active muscles for transfer.

The aim is to provide a key grip of thumb to index (Fig. 4, Fig. 5). If more motors are available, the provision of finger flexion will be the next aim, and then the possibility of restoring the thumb adduction. Often passive digital extension can be obtained through dorsal extension tenodeses.

This is not the place to describe the almost unlimited variations now possible in the rapidly expanding field of this quite special hand surgery. Only a few examples will be shown. It should not be forgotten, that it is the patients with higher cord lesions who need help most and for them usually only a key grip is possible. This provides broader grip surfaces than an opposition grip and is a great advantage compared with the two-hand grip used earlier which is very clumsy. Not infrequently tactile gnosis and proprioception is gone from both hands and as vision cannot focus on more than one hand at a time usually only one of the hands can be given a useful grip. This should always be the best hand, but still it is useful to restore elbow extension on both sides.

Experience is necessary to handle the patients' general problems and particularly an unrealistic expectation of what the surgeon can achieve. An important 


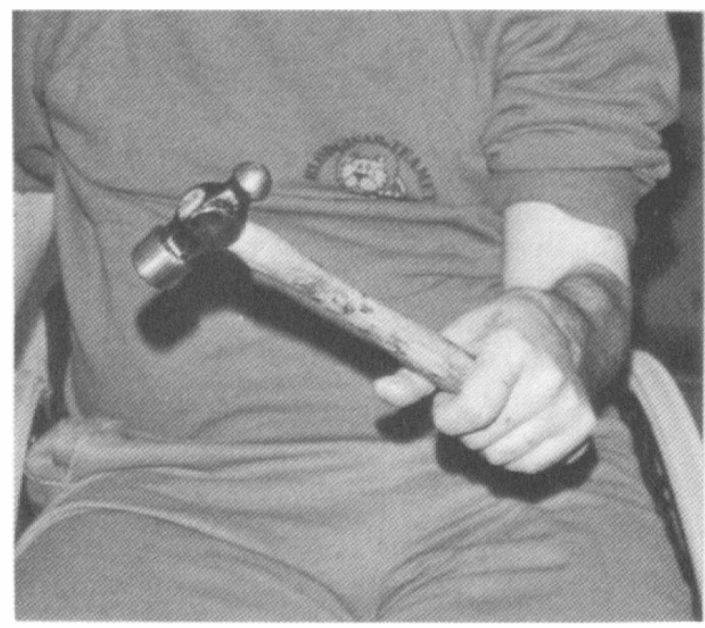

Figure 5 Another flexor function obtained in the same way.

part of the surgeon's work is to counteract the patients desire to get as much surgery as possible performed at the one time. Such a desire may lead to disappointment.

It has taken some 15 years to get to the present position where many centres are working in this field. Wide experience has been gained so far only in Argentina, Finland, Scotland, Sweden and the U.S.A. and perhaps also in France and Japan.

Most interesting work on electrical stimulation of muscles goes on especially in the U.S.A. It is not yet developed enough to be brought into general active use but it seems not impossible that the future will see it used, probably in combination with surgery.

Total progress in this field is rapid and no doubt new methods will soon be added, especially useful for the higher cord lesions. It is very satisfactory that it can now be stated, following the principles here presented, that there is hardly a field of surgery, where the risks of complications and of functional loss are as low as here. The basis for this statement is a personal experience now of 81 operations to restore elbow extension and 171 hand grip constructions, with many others performed by colleagues. Good follow-up studies have been presented, showing that the long term results remain stable.

\section{References}

De Benedetti M 1979 Restoration of elbow extension power in the tetraplegic patient using the Moberg technique. Fournal of Hand Surgery 4:86-89

FREeHAFER AA, VONhaM E, Allen V 1974 Tendon transfers to improve grasp after injuries of the cervical spinal cord. Fournal of Bone and foint Surgery 56A:951-959

Freehafer AA, Peckham PH, KeIth MW 1979 Determination of muscle-tendon unit properties during tendon transfer. Fournal of Hand Surgery 4:331-339

HENTZ VR, KEOSHIAN LA 1979 Changing perspectives in surgical hand rehabilitation in quadriplegic patients. Plastic $\mathcal{E}$ Reconstructive Surgery 509

HeNTZ VR, BRAUN M, KeOShIAN LA 1983 Upper limb reconstruction in quadriplegia; Functional assessment and proposed treatment modifications. Fournal of Hand Surgery 8A:119-130 
House JH, GWATHEY FW, LUNDSGAARD DK 1976 Restoration of strong grasp and lateral pinch in tetraplegia due to spinal cord injury. Fournal of Hand Surgery 152-159

HOUSE JH, SHANNON MA 1985 Restoration of strong grasp and lateral pinch in tetraplegia: a comparison of two methods of thumb control in each patient. Fournal of Hand Surgery 10A:2229

LAMB DW, CHAN KM 1983 Surgical reconstruction of the upper limb in traumatic tetraplegia. A review of 41 patients. Fournal of Bone and foint Surgery 65B:291-298

MCDowell CL, Moberg E, SMITH AG 1979 International conference on surgical rehabilitation of the upper limb in tetraplegia. Fournal of Hand Surgery 4:387-390

MCDowell CL 1983 Tetraplegia, In: GREEN DP Operative Hand Surgery Vol. 2, pp. 1109-1127

MCDowell CL, Moberg E, House JH 1986 The second international conference on upper limb rehabilitation of the upper limb in tetraplegia. Fournal of Hand Surgery 11A:604-608

MOBERG E 1975 Surgical treatment for absent single hand grip and elbow extension in quadriplegia. Fournal of Bone and foint Surgery 57A:196-206

MOBERG E 1976 Reconstructive hand surgery in tetraplegia, stroke and cerebral palsy: some basic concepts in physiology and neurology. Fournal of Hand Surgery 1:29-34

MOBERG E 1978 The upper limb in tetraplegia, a new approach to surgical rehabilitation. Thieme, Stuttgart.

MOBERG E The role of cutaneous afferents in position sense, kinaesthesia and motor function of the hand. Brain 106:1983

MOBERG E The surgery of the spastic, stroke and tetraplegic hand. In Converse: Reconstructive Plastic Surgery, Second edition. In press

MOBERG E 1987 Current treatment programme using tendon surgery in tetraplegia. In: HUNTER et al. Hand Tendon Surgery, Mosby, St. Louis

ZANCOLLI E Structural and dynamic bases of hand surgery. 2nd edition, Lippingcott, Philadelphia, 1979 